\title{
ЭКОЛОГИЧЕСКИЕ ЦЕННОСТИ КАК ОСНОВА ЭКОЛОГИЧЕСКОГО ОБРАЗОВАНИЯ ДЛЯ УСТОЙЧИВОГО РАЗВИТИЯ
}

\section{ENVIRONMENTAL VALUES AS A BASIS OF ENVIRONMENTAL EDUCATION FOR SUSTAINABLE DEVELOPMENT}

N. Melnik

E. Purgina

Summary: The article discusses theoretical problems of environmental education in the light of sustainable development and the reasons for further transformation of environmental education's goals. Environmental culture is considered to be the most promising target of environmental education. A special emphasis is made on the system of environmental values, which lies at the core of environmental culture. To realize the goals of environmental education most effectively it is necessary to clarify the environmental component in the Federal State Educational Standard for Basic Secondary Education and to develop adequate pedagogical methods and techniques within the framework of system-activity and cultural-historical approaches.

Keywords: environmental values, environmental culture, environmental education, education for sustainable development.
$\mathrm{B}$ о второй половине XX века обострились глобальные экологические проблемы. Это породило интерес к поискам модели развития цивилизации, которая бы обеспечивала потребности человечества к динамичному развитию, но не приводила бы к конфликту в рамках биосферной системы.

В качестве стратегического решения данной проблемы в конце 1980-х гг. Международной комиссией по окружающей среде и развитию была предложена концепция устойчивого развития. В 1992 г. на Конференции ООН по окружающей среде и развитию (Рио-де-Жанейро) программа действий по реализации концепции устойчивого развития одобрена главами большинства стран мира, включая Россию. В 2005 г. Европейская экономическая комиссия ООН приняла Стратегию в области образования в интересах устойчивого развития, суть которой состоит в том, чтобы перейти от простой передачи знаний и навыков, необходимых для существования в современном обществе, к способности действовать и жить в быстро меняющихся условиях, участвовать в планировании социального развития, учиться предвидеть последствия предпринимаемых действий, в том числе и возможные последствия в сфере устойчивости природных экосистем и социальных структур. 57-я сессия Генеральной Ассамблеи ООН объявила десятилетие 2005-
Мельник Наталья Борисовна

К.ф.н., дочент, Уральский федеральный университет им. первого Президента России Б.Н. Ельцина,

2. Екатеринбург

eco_nataly@mail.ru

Пургина Елена Ивановна

К.ф.н., дочент, Уральский институт Государственной противопожарной службы МЧС России, г. Екатеринбург purgina.elena@mail.ru

Аннотация: В статье рассматриваются теоретические проблемы экологического образования в контексте концепции устойчивого развития. Анализируются причины трансформации целей экологического образования. Экологическая культура представлена как наиболее перспективная цель экологического образования. Акцент сделан на системе экологических ценностей, являющихся ядром экологической культуры. Эффективная реализация целей экологического образования возможна при уточнении экологической компоненты содержания образования в ФГОС 000, развития адекватных педагогических методов и средств на основе системно-деятельностного и культурно-исторического подходов.

Ключевые слова: экологические ценности, экологическая культура, экологическое образование, образование для устойчивого развития.

2014 гг. Декадой образования в интересах устойчивого развития.

Устойчивое общество - это общество, сохраняющееся в течение жизни многих поколений и обладающее достаточной дальновидностью, гибкостью и мудростью, чтобы не подрывать свои физические или социальные системы жизнеобеспечения. Образование в интересах устойчивого развития отражает смысл исходного понятия «устойчивое развитие», которое определяется как развитие, удовлетворяющее потребности настоящего времени, не ставя под угрозу возможности будущих поколений удовлетворять их собственные потребности. Устойчивое развитие представляет собой комплексную проблему, охватывающую экономические, экологические и социальные аспекты. Иными словами, развитие необходимо для удовлетворения потребностей людей и улучшения качества их жизни. В то же время развитие должно основываться на эффективном и ответственном использовании всех имеющихся у общества ограниченных ресурсов - природных, людских и экономических $[8,16,19]$. Концепция устойчивого развития предполагает совместное рассмотрение интересов, мнений, норм и ценностей и поэтому формируется на основе диалога между различными участниками. 
В настоящее время образование в интересах устойчивого развития продолжает формироваться в качестве всеобъемлющей программы, позволяющей решать вопросы индивидуализации образования, а также связанные между собой экологические, социальные и экономические проблемы. Это подтверждено принятием Боннской декларации в рамках Всемирной конференции ЮНЕСКО по образованию в интересах устойчивого развития (2009 г.). В 2012 году в Рио-де-Жанейро прошла Конференция ООН по устойчивому развитию (РИО+20), где было подтверждено, что одним из главных инструментов формирования устойчивого развития общества является экологическое образование.

Многочисленные документы и соглашения в области образования в интересах устойчивого развития остаются добровольными и рамочными, не имеющими юридической силы. Тем не менее, они действуют на глобальном, региональном, национальных уровнях, определяя не только направления работы, но и государственную и международную политику в этой области. В Федеральном законе «Об охране окружающей среды» (2002г.) сказано, что в целях формирования экологической культуры и профессиональной подготовки специалистов устанавливается система всеобщего и комплексного экологического образования [18]. В документе «Основы государственной политики в области экологического развития Российской Федерации на период до 2030 года» (2012 г.) поставлен ряд конкретных задач, связанных с развитием экологического образования и просвещения, в том числе, обеспечение направленности процесса воспитания и обучения в образовательных учреждениях на формирование экологически ответственного поведения, в том числе посредством включения в федеральные государственные образовательные стандарты соответствующих требований к формированию основ экологической грамотности у обучающихся $[10,8]$.

Идея о приоритетности образования в ситуации экологического кризиса потребовала разработки системы экологического образования не только на уровне социальных институтов, но и как полноценной педагогической системы. Это предполагает разработку всех элементов педагогического процесса в их функциональной, ценностной и информационной взаимосвязи. И прежде всего, встала задача определения цели современного экологического образования.

В истории экологического образования можно наблюдать трансформацию цели экологического образования. Первоначально в качестве цели экологического образования была принята экологическая грамотность, экологическая просвещенность, экологическая обученность. В последующий период желаемым результатом экологического образования стали считать развитое чувство природы, любовь к природе. Наконец, целью экологического образования была признана экологическая ответственность, а позже - экологическая компетентность.

Нам представляется, что в основе целеполагания в области экологического образования должно лежать понятие «экологическая культура» [7]. Экологическая культура выступает интегральной характеристикой как общества в целом, так и определенной социальной группы или конкретной личности. Такая внемасштабность экологической культуры облегчает перевод широкой социальной проблемы взаимодействия общества и природы в профессионально-педагогическую плоскость.

В этом контексте проблема экологического кризиса представляется как проблема экологической культуры общества в конкретный период существования. Сущность ее заключается в неадекватности экологической культуры общества условиям окружающей среды и проявляется в неустойчивости господствующего типа антропоэкосистемы. Выход из экологического кризиса в этом случае может означать выработку в обществе иного (нового, более адекватного среде, т.е. адаптивного) уровня и характера экологической культуры. Задача образования - в формировании этого типа культуры, передаче этой культуры новому поколению. Важно сформировать у представителей молодого поколения отдельные элементы знаний, умений и навыков, сохраняя при этом целостность личности. Это позволит осуществлять поддерживающее динамическое равновесие между природой и обществом, т.е. достичь экологической гармонии.

В прошлом тысячелетии понятие «экологическая культура» имело конкретно-историческое звучание. Экологическая культура понималась как ожидаемая в перспективе стадия развития отношений между природой и обществом и определялась как высокая экологическая образованность, сознательное отношение к природе, практическое участие в улучшении природопользования. Часто экологическую культуру интерпретировали как использование окружающей природной среды на основе познания естественных законов развития природы с учетом ближайших и отдаленных последствий изменения природной среды под влиянием человеческой деятельности $[3,12,5]$.

Эта точка зрения заставляет признать отсутствие экологической культуры у всех предыдущих поколений и считать ее лишь ожидаемым и желаемым состоянием культуры. Но очевидное разнообразие типов и стилей взаимодействия с природой в различных культурах и в разные исторические периоды с необходимостью приводит к неоценочному, внеисторическому и внегеографическому толкованию экологической культуры. Экологическая культура как аспект общей культуры, отражающий характер взаимодействия субъекта (обще- 
ства, социальной группы, индивида) с природой, можно наблюдать во всех исторических типах обществ, т.е. экологическая культура была, есть и будет у всех племен, народов, государств во все времена. Можно говорить об экологической культуре в архаическом обществе, в Древней Греции, равно как и описывать экологическую культуру современного общества или прогнозировать экологическую культуру общества будущего[17].

Под экологической культурой мы понимаем способ и характер взаимодействия человека (общества) с окружающей природной средой, включающий конкретный уровень и характер экологических знаний, экологических ценностей и практику (технологии и принципы) природопользования. Таким образом, экологическая культура как способ взаимодействия человека (общества) и окружающей природной среды, способ природопользования включает следующие компоненты:

1. духовно-теоретический - совокупность представлений о взаимосвязях в системе «человек - природа» и в самой природе (экологическое знание); экологические знаки и символы;

2. духовно-практический - установки и ценностные ориентации, в свете которых воспринимается и оценивается природа (экологические ценности), а в результате конструируется поведение относительно природы; отношения к природе, обществу и человеку; нормативные запреты и предписания, регулирующие взаимодействие человека с природой;

3. материально-практический - совокупность реальных стратегий и технологий взаимодействия с природой, природопользования и природосбережения; обряды и обычаи, посредством которых оформляются соответствующие действия относительно природы; социальные институты, в рамках которых протекает и которыми регулируется взаимодействие в системе «человек - природа».

В рамках этого подхода можно говорить об экологической культуре общества в целом, экологической культуре каких-либо социальных групп и экологической культуре конкретной личности. Предложенная структура экологической культуры в индивидуально-личностном масштабе соотносима со структурой личности. Среди множества структурных элементов психологи обращают внимание на интеллектуальную сферу, эмоционально-ценностную и поведенческую сферы личности $[1,2,4]$. Это позволяет выделить в структуре экологической культуры личности следующие сферы:

1. информационно-интеллектуальную (экологические знания),

2. эмоционально-ценностную (экологические ценностные ориентации),

3. деятельностно-волевую (экологическая деятельность).
Такое соответствие структуры экологической культуры общества элементам экологической культуры личности закладывает основу эффективного педагогического воздействия при формировании экологической культуры и определяет структуру содержания экологического образования.

Формирование новой экологической культуры у подрастающего поколения является целью национальной экологической политики в сфере образования. Современное среднее образование, а также высшее профессиональное образование информационного общества ориентированы прежде всего на информационную составляющую. Ценностный и деятельностный компонент содержания образования по-прежнему не являются ведущими. Многочисленные попытки модернизации образования, например, переход на компетентностную модель, оставляют незыблемым приоритет знания как ведущего результата образования.

Однако, по мнению психологов и философов, ядром личности является его система ценностей. Ценности, как системообразующий элемент структуры личности, влияют на приобретение знаний и приобщение к деятельности. Ценности становятся своеобразным фильтром проникновения в информационно-интеллектуальную сферу личности предлагаемых обществом, в том числе образовательными структурами, знаний. Ценности также стимулируют человека для участия лишь в той деятельности, которая соответствует ценностным ориентациям человека и воспринимается им как позитивная, являясь основой его существования $[6,11,15]$.

Понятие «ценность» настолько сложно и неоднозначно, что не поддаётся исчерпывающему концептуальному выражению. Ценность несводима ни к потребностям, ни к желаемости, ни каким-либо другим психофизиологическим качествам и феноменам. Однако психологи убеждены, что ценности

- надситуативны, т.е. не ограничены лишь ситуацией, а определяют жизнь человека во всех ситуациях;

- являются критерием выбора и оценки для человека;

- вызывают эмоционально окрашенную реакцию человека на события и объекты, выражающие или попирающие эти ценности;

- определяют цели человека, направляют его поведение, являются ориентиром, идеалом, руководящим принципом;

- содержат представления о том, что имеет определенную жизненную цену и способно удовлетворять интересы и потребности человека, социальной группы, общества;

- взаимосвязаны между собой, иерархизированы, разномасштабны и представляют систему. 
Среди разнообразных ценностей (политических, религиозных, моральных, эстетических...) экологические ценности занимают особое место. Они носят интегральный характер, так как одновременно являются витальными, социальными, моральными и эстетическими, поскольку отражают разнообразные отношения человека к природе и природным объектам, а также к человеку, его месту в природе и деятельности природопользования [14].

Сущность аксиологического подхода в образовании заключается в ориентации всей образовательной системы на развитии у человека заданной системы ценностей, определении его нравов, формировании определенного отношения к миру и его проявлениям. Нам представляется, что в структуре экологической культуры экологические ценности являются системообразующим элементом, поскольку определенное отношение задает избирательность восприятия, активно влияет на информационно-интеллектуальную сферу. В то же время именно отношение ориентирует человека в разнообразии вариантов деятельности, великом множестве возможных поступков, помогая осуществить выбор, а значит предпочесть тот или иной характер деятельности, поступить так или иначе. Достаточно сравнить системы экологических ценностей лишь нескольких исторических периодов, чтобы понять влияние ценностных ориентиров на конкретную практику жизни, технологии природопользования, а в итоге - на общий характер культуры.

В системе экологических ценностей можно выделить:

- ценность живого (восприятие живого как ценного и характер этой ценности);

- ценность природы вообще (восприятие природы исключительно как утилитарной ценности, обнаружение в природе эстетической, сакральной, санитарно-гигиенической, познавательной ценности);

- ценность человека относительно природы (определение позиции человека в мироздании, отношение к месту человека в мире природы, относительно мира природы);

- ценность деятельности природопользования (восприятие определенной деятельности в природе как позитивной или негативной, критерии и показатели этой ценности);

- ценность здоровья.

Каждая культурная эпоха характеризуется специфическим набором и иерархией ценностей, в которых фиксированы критерии социально признанного данным обществом поведения. В системе экологических ценностей отражается общая мировоззренческая установка эпохи и становится очевидной высшая ценность.
Современная культура по-прежнему, остается антропоцентрической. Антропоцентризм дал всплеск общественного развития, породил удивительную культуру, обеспечившую на некоторое время комфорт человеческого существования. Но к настоящему моменту антропоцентрическая культура исчерпала себя и породила массу проблем, в том числе вызвала экологический кризис. Современная культура не позволяет адаптироваться человечеству в новой реальности, им же самим и созданной. Необходимо создание новой экологической культуры, что предполагает выработку иной системы экологических ценностей.

Задача образования в переходный период от одного типа экологической культуры к другому заключается не в том, чтобы передавать новым поколениям старые отжившие экологические ценности. Миссия образования в период экологического кризиса - в том, чтобы обеспечить становление у подрастающего поколения новой системы экологических ценностей. Эти новые экологические ценности пока неясно формулируются, трудно определяются, но, несомненно, начинают проявляться в современной культуре ростками нового, признаками будущего.

Экологическое образование в интересах устойчивого развития - это процесс, продолжающийся на протяжении всей жизни, начиная с раннего детства до получения высшего образования и образования для взрослых, и выходит за пределы формального образования. Поскольку система ценностей, образ жизни и жизненные установки формируются в раннем возрасте, особое значение приобретает образование для детей $[16,19]$.

Для эффективной реализации целей экологического образования необходимо определить его специфику и статус этой экологической компоненты в контексте содержания образования. ФГОС второго поколения предусматривает реальные механизмы, условия и средства решения этой задачи - на основе системно-деятельностного и культурно-исторического подходов. Можно утверждать, что в первых десятилетиях XXI века в образовании сложились предпосылки новой модели экологического образования. Механизмом перехода к новой модели экологического образования выступает системно-деятельностный подход, предусматривающий целенаправленное развитие разных сфер личности обучающегося посредством освоения им универсальных учебных действий. Анализируя задачи примерных программ по базовым учебным курсам, можно констатировать, что они содержат задачи экологического образования, а именно: формирование «основ экологического сознания на основе признания ценности жизни во всех ее проявлениях, необходимости ответственного, бережного отношения к окружающей среде», «основ экологической грамотности»; «экологического мышления, чен- 
ностного отношения к природе и жизни»; «целостного восприятия мира как иерархии формирующихся и развивающихся по определенным законам взаимосвязанных природно-общественных территориальных систем...»; «умений анализировать и планировать экологически безопасное поведение в целях сбережения здоровья и окружающей среды»; «осознания главных особенностей и проблем взаимодействия природы и общества ..., подходов к устойчивому развитию территорий». Отметим, что стандартом не только предусматривается механизм достижения этих задач, но и технологичные способы измерения их решения [13].

В заключении важно подчеркнуть, что и познание определяется системой ценностей. В новом этапе экологической культуры, в формирующейся экологической культуре будущего природа должна восприниматься как универсальная ценность, а значит, занять особое место в структуре учебного знания. Логика - от мертвой природы как ресурса к живой природе как ресурсу, а затем к человеку и обществу как вершине мира - поддерживает антропоцентрические ценности и не может воспроизводиться в образовании, ориентированном на устойчивое развитие.

Новая система экологических ценностей должна повлиять и на систему деятельности, организуемой в системе образования. Это не может быть только познавательная деятельность, подтверждающая познавательную ценность природы. Универсальная ценность природы должна проявляться и в разнообразной деятельности обучающихся - эстетической, санитарно-гигиенической, нравственной - отражающей эстетическую, санитарногигиеническую и нравственную ценность природы.

ЛИТЕРАТУРА

1. Burns R. Self-concept development and education. London: Holt, Rinehart and Winston, 1982.

2. Burns R. The self-concept// Essential Psychology. Dordrecht: Springer, 1980. P.171-196.

3. Гирусов Э.В. Экологическое сознание как условие оптимального взаимодействия общества и природы//Философские проблемы глобальной экологии. M., 1983.

4. Дерябо С.Д., Ясвин В.А. Экологическая педагогика и психология. Ростов на Дону: Феникс, 1996.

5. Захлебный А.Н.,Суравегина И.Т. Экологическое образование школьников во внеклассной работе: пособие для учителя . М.: Просвещение,1984.

6. Крюков В.В. Введение в аксиологию.- Новосибирск,2001.

7. Мельник Н.Б. Экологическая культура //Философский словарь по правам человека. Екатеринбург: изд-во АМБ, 2007. С. 664-667.

8. На пути к устойчивому развитию России. Бюллетень Центра экологического развития России.- Издательская группа «Реформ-Пресс», 2006, №34.

9. Ногтева Е.Ю., Лушников И.Д. Развитие экологической культуры учащихся. -Вологда, 2006.

10. Основы государственной политики в области экологического развития Российской Федерации на период до 2030 года (30.04.2012). URL:http://www. consultant.ru/cons/cgi/online.cgi?req=doc\&base $=L A W \& n=129117 \& f l d=134 \& d s t=1000000001,0 \&$ rnd $=0.6983266262511691 \# 0$

11. Панов В.И. Введение в экологическую психологию: Учебное пособие. -М., 2006.

12. Plumwood, V. Environmental Culture: The Ecological Crisis of Reason. London, New York: Routledge, 2002.

13. Примерная основная образовательная программа образовательного учреждения. Основная школа / [сост. Е.С. Савинов]. М.: Просвещение, 2011.

14. Reser J.P., Bentrupperbäumer J.M. What and where are environmental values? Assessing the impacts of current diversity of use of 'environmental' and 'World Heritage' values// Journal of Environmental Psychology. 2005. № 25(2). P.125-146.

15. Смолова Л.В. Введение в психологию взаимодействия с окружающей средой. - СПб., 2008.

16. Sauvé L. Environmental Education and Sustainable Development: A Further Appraisal// Canadian Journal of Environmental Education. 1996. № 1. P. 7-34.

17. Товбина В.Л. Экологическая культура: понятие и проблемы становления//Уч. зап. РГГМУ, 2006, № 2, с. 255-264.

18. Федеральный закон №7-Ф3 от 10 января 2002 г. «06 охране окружающей среды», ст. 71, гл. XII. URL: http://www.referent.ru/1/78524

19. Fien J., Heck D. Environmental Education and Education for Sustainable Development// International Handbook of Educational Research in the Asia-Pacific Region. Dordrecht: Springer-Science+Business Media, B.V., 2003. P. 569-584. 